\title{
Four-year effects of exercise on fatigue and physical activity in patients with cancer
}

Lenja Witlox', Anouk E. Hiensch', Miranda J. Velthuis², Charlotte N. Steins Bisschop' ${ }^{1}$, Maartje Los ${ }^{3}$, Frans L. G. Erdkamp ${ }^{4}$, Haiko J. Bloemendal ${ }^{5}$, Marlies Verhaar ${ }^{6}$, Daan ten Bokkel Huinink', Elsken van der Wall ${ }^{8}$, Petra H. M. Peeters ${ }^{1}$ and Anne M. May ${ }^{1 *}$

\begin{abstract}
Background: In the earlier randomized controlled Physical Activity during Cancer Treatment (PACT) study, we found beneficial effects of an 18-week supervised exercise program on fatigue in patients with newly diagnosed breast or colon cancer undergoing adjuvant treatment. The present study assessed long-term effects of the exercise program on levels of fatigue and physical activity 4 years after participation in the PACT study.

Methods: The original study was a two-armed, multicenter randomized controlled trial comparing an 18-week supervised exercise program to usual care among 204 breast cancer patients and 33 colon cancer patients undergoing adjuvant treatment. Of the 237 PACT participants, 197 participants were eligible and approached to participate in the 4-year post-baseline measurements, and 128 patients responded. We assessed fatigue and physical activity levels at 4 years post-baseline and compared this to levels at baseline, post-intervention (18 weeks post-baseline), and at 36 weeks post-baseline.

Results: Intention-to-treat mixed linear effects model analyses showed that cancer patients in the intervention group reported significantly higher moderate-to-vigorous total physical activity levels ( $141.46 \mathrm{~min} /$ week (95\% confidence interval $(C l) 1.31,281.61$, effect size $(E S)=0.22$ ) after 4 years compared to the usual care group. Furthermore, cancer patients in the intervention group tended to experience less physical fatigue at 4 years postbaseline compared to the usual care group $(-1.13,95 \% \mathrm{Cl}-2.45,0.20, \mathrm{ES}=0.22)$, although the result was not statistically significant.

Conclusion: Patients with breast or colon cancer who participated in the 18-week exercise intervention showed significant higher levels of moderate-to-vigorous total physical activity levels and a tendency towards lower physical fatigue levels 4 years post-baseline. Our result indicate that exercising during chemotherapy is a promising strategy for minimizing treatment-related side effects, both short and long term.
\end{abstract}

Trial registration: Current Controlled Trials ISRCTN43801571, Dutch Trial Register NTR2138. Trial registered on 9 December 2009.

Keywords: Cancer, Exercise intervention, Chemotherapy, Fatigue, Physical activity, Long-term effects

\footnotetext{
* Correspondence: A.M.May@umcutrecht.nl

${ }^{1}$ Department of Clinical Epidemiology, Julius Center for Health Sciences and

Primary Care, University Medical Center Utrecht, Utrecht University, PO Box

85500, STR 6.131, 3508 GA Utrecht, The Netherlands

Full list of author information is available at the end of the article
}

(c) The Author(s). 2018 Open Access This article is distributed under the terms of the Creative Commons Attribution 4.0 International License (http://creativecommons.org/licenses/by/4.0/), which permits unrestricted use, distribution, and reproduction in any medium, provided you give appropriate credit to the original author(s) and the source, provide a link to the Creative Commons license, and indicate if changes were made. The Creative Commons Public Domain Dedication waiver (http://creativecommons.org/publicdomain/zero/1.0/) applies to the data made available in this article, unless otherwise stated. 


\section{Background}

Cancer-related fatigue is the most common and distressing treatment-related side effect. It may persist for many years and result in impairment of quality of life and physical functioning [1-3]. Increasing evidence suggests that exercise interventions delivered during adjuvant cancer treatment have beneficial short-term effects on fatigue in cancer patients [4, 5].

Between 2010 and 2013, we performed the randomized controlled Physical Activity during Cancer Treatment (PACT) study and found lower levels of physical fatigue after an 18-week supervised exercise intervention delivered during adjuvant treatment in patients with breast or colon cancer [6, 7]. The PACT intervention included both aerobic and resistance training at a moderate-to-high intensity and also incorporated principles of Bandura's social cognitive theory to help participants maintain a physically active lifestyle after completion of the exercise program [8]. Maintaining a physically active lifestyle into survivorship might positively influence fatigue levels in the long term.

Since there have been notable improvements in cancer survival rates, and cancer treatment is known to have long-lasting side effects including fatigue, it is important to gain more insight into the potential effects of exercising during treatment on fatigue years after completion of adjuvant cancer treatment $[4,9,10]$. Most randomized controlled trials (RCTs) followed participants up to 6 months post-intervention and showed trends of decreased fatigue in favor of the exercise intervention group [11-13]. Only one intervention study followed previous breast cancer study participants for 5 years. The researchers found that women in the intervention group reported more time spent in leisure-time activities, more periods with positive mood, and more favorable motivational outcomes compared to the control group $[14,15]$. Long-term effects on fatigue were not assessed.

Therefore, the aim of the present study is to assess long-term effects of the PACT exercise intervention on fatigue (the primary outcome of the original PACT study) and physical activity levels. These measurements were taken on average 4 years after enrollment in the PACT study.

\section{Methods}

\section{Settings and participants}

A detailed description of the PACT study design has been published previously [16]. The original study was conducted in seven hospitals in the Netherlands between 2010 and 2013. In short, this multicenter controlled trial randomly assigned 204 breast and 33 colon cancer patients to either usual care $(n=118)$ or to supervised aerobic and muscle strength training in addition to usual care $(n=119)$. Inclusion criteria were as follows: a histological diagnosis of cancer less than 6 weeks (breast cancer) or 10 weeks (colon cancer) before study recruitment; stage M0; scheduled for chemotherapy; age 2575 years; not treated for any cancer in the preceding 5 years (except basal skin cancer); able to read and understand the Dutch language; Karnovsky Performance Status of $\geq 60$; able to walk 100 m or more; and no contraindications for physical activity (as assessed through the Revised Physical Activity Readiness Questionnaire). After written informed consent was obtained, a concealed computer-generated randomization, following a 1:1 ratio and stratified for age (25-40, 40-65, and 6575 years), adjuvant treatment (radiotherapy yes/no before chemotherapy), use of tissue expander (for breast cancer patients yes/no), tumor type, and hospital, was used to allocate patients to the two groups. The study was approved by the Medical Ethics Committee of the University Medical Center Utrecht and the local ethical boards of the participating hospitals.

Three to four years after inclusion in the original PACT study, the treating physicians approached 197 PACT participants again for information on their current health status. The present study was originally not planned when participants were recruited for the PACT study, and consent was asked again. Eleven participants were deceased or otherwise considered not healthy enough to participate by the treating oncologist (Fig. 1). We did not invite participants who dropped out of the intervention and/or did not perform the evaluation measurements during the original PACT study and also indicated they were not willing to complete questionnaires at subsequent time points. We also excluded participants who were not willing to be invited to future research $(n=28)$. Participants who dropped out during the original PACT study but indicated they were willing to complete questionnaires at all subsequent time points were invited. Patients who signed written informed consent were asked to complete questionnaires at home.

\section{Intervention}

The exercise intervention consisted of an 18-week supervised aerobic and muscle strength exercise program in addition to the usual care. Twice a week participants attended a 1-h session supervised by a physiotherapist. The aerobic and muscle strength exercises were individualized to the participants' preferences and fitness levels as assessed by a cardiopulmonary exercise test and a one-repetition maximum muscle strength test. In addition to the intervention, participants were asked to be physically active for at least $30 \mathrm{~min}$ a day on 3 other days of the week according to the Dutch guideline for physical activity [17]. Principles of Bandura's social cognitive theory were incorporated to promote maintenance of a physically active lifestyle [8]. This theory emphasizes the role of cognitive processes in determining behavior such as exercise. The most important construct in this theory is self-efficacy, which can be altered by 


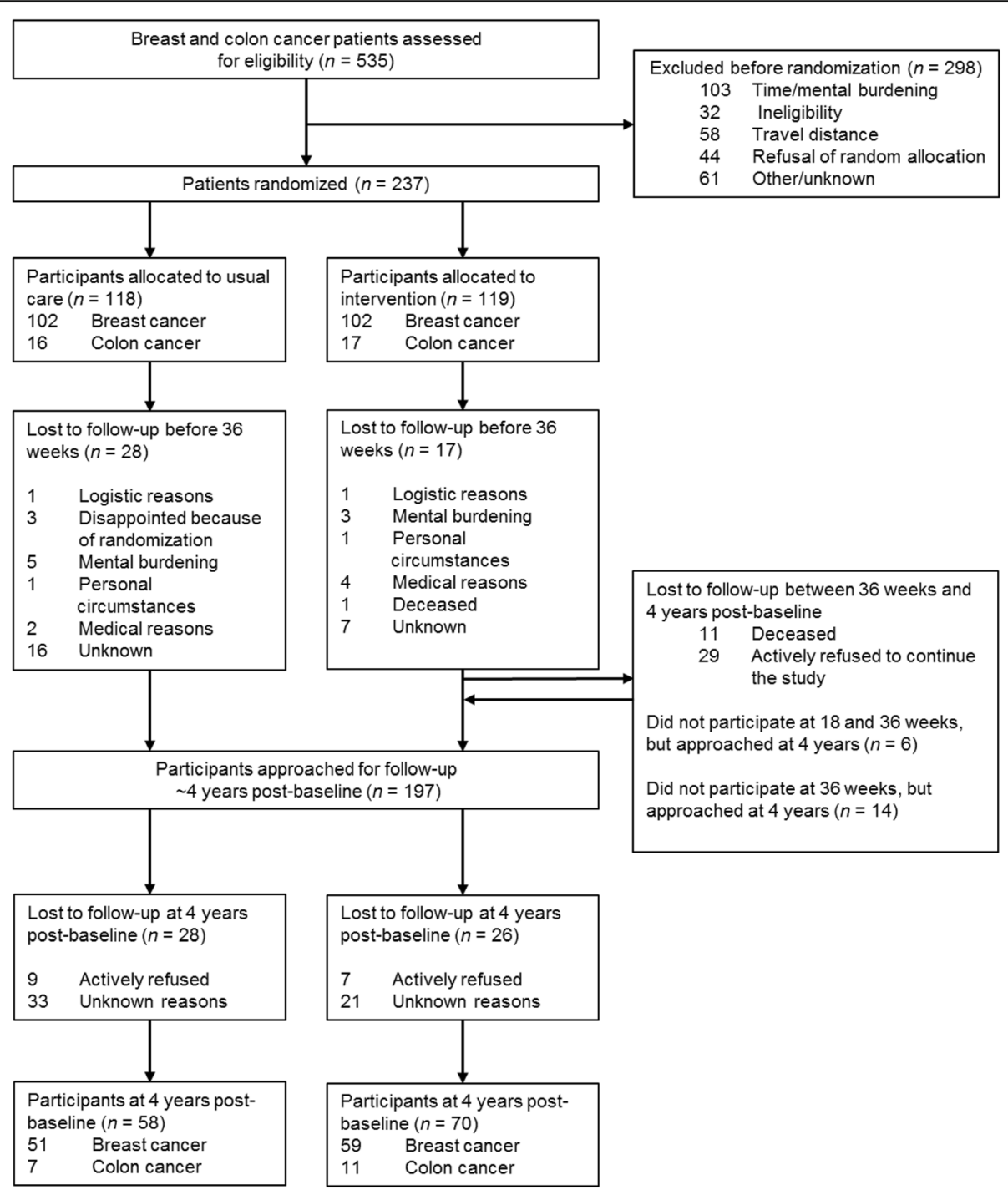

Fig. 1 Participant flow through the study

mastery experience, vicarious or observational learning, and verbal persuasion. First, mastery experience was used by asking participants to report training results in graph form. Second, physiotherapists checked the graphs weekly, gave positive feedback about the obtained results, and stimulated the participant to make action plans to further increase their physical activity level.

Participants in the control group received the usual care and were asked to maintain their habitual physical activity pattern up to week 18 . Thereafter they were allowed, for ethical reasons, to participate in exercise programs offered in the Netherlands to patients with cancer after completion of primary treatment.

\section{Outcome measures}

The outcomes were assessed at baseline, post-intervention (18 weeks post-baseline), and at 36 weeks (post-baseline) in the original PACT study. In the present study, outcomes were measured at a median of 4 years post-baseline.

\section{Fatigue}

Fatigue was assessed using the validated Dutch version of the Multidimensional Fatigue Inventory (MFI) [18]. The MFI is a 20-item questionnaire and consists of five dimensions: general fatigue, physical fatigue, mental fatigue, reduced activity, and reduced motivation. Scores of the subscales range from 4 to 20 , and a higher score indicates higher levels of fatigue.

\section{Physical activity}

Physical activity levels were assessed using the Short Questionnaire to Assess Health-enhancing physical activity (SQUASH) [19]. The validated four-item questionnaire contains questions about commuting, leisure time 
and sports, household activities, and activities at work and school. For each activity, duration, frequency, and intensity are assessed. At baseline, we asked participants to fill in their physical activity level for a usual week in the months preceding study entry. Minutes per week of moderate-to-high intensity total physical activity and leisure-time and sport activity were calculated. Moderate-to-high intensity physical activity was defined as $\geq 4$ metabolic equivalent (METs).

\section{Statistical analysis}

Sample size calculations were performed for the original PACT study with fatigue at 18 weeks (post-intervention) as the primary outcome. In order to detect a between-group change in fatigue of 2 units $( \pm 4$ standard deviation (SD)), corresponding to a medium effect size (ES), and anticipating a drop-out of $10 \%, 75$ participants in the intervention group and 75 participants in the usual care group were needed $(\alpha=0.05$, power $=0.80)$. Taking the correlation $(\rho)$ between baseline and follow-up measurements into account by multiplying the previously calculated number of subjects by $\left(1-\rho^{2}\right)$, plus one extra subject per group [20], yielded a sample size of 64 participants per group, which enables us to detect similar ESs. Note that here we analyzed data for breast and colon cancer patients together, in contrast to the original PACT study.

Baseline demographics were summarized for all breast and colon cancer patients together and compared for those who had and had not dropped out of the study 4 years post-baseline. Intention-to-treat mixed linear regression models were used to model fatigue and physical activity at 18 weeks, 36 weeks, and 4 years for all breast and colon cancer patients combined and for breast cancer patients only. These models were adjusted for the baseline value of the outcome and tumor receptor status (triple negative; Her2Neu+, estrogen receptor (ER)+ or progesterone receptor (PR)+; Her2Neu+, ER- and PR-; Her2Neu-, ER+ or $\mathrm{PR}+$ (for breast cancer patients)) as well as for the stratification factors: age (25-40, 40-65, and 65-75), adjuvant treatment (radiotherapy yes/no before chemotherapy), hospital, tumor site, and use of tissue expander (for breast cancer patients yes vs. no). Between-group differences were modeled using outcome measurements obtained at 18 weeks (post-intervention), and 36 weeks and 4 years post-baseline. Within-group differences were modeled using outcome measurements obtained at all four time points (i.e., at baseline, 18 weeks, 36 weeks, and 4 years). Analyses were performed on an intention-to-treat basis for all 237 breast and colon cancer patients in the original PACT study with at least one measurement, except when this was the baseline value. The model accounts for missing data by taking the individual time trends and the observed group means at each time point into consideration to provide a more accurate estimate of the population mean at each time point.
Mean differences and 95\% confidence intervals (CIs) were accompanied by standardized ESs. The standardized ESs were calculated by dividing the adjusted between-group difference of the 4-year post-baseline mean by the pooled baseline standard deviation. According to Cohen, ESs $<0.2$ indicate "no difference," whereas ESs between 0.2 and 0.5 indicate "small differences," ESs between 0.5 and 0.8 indicate "medium and clinically relevant differences," and ESs $\geq 0.8$ indicate "large differences" [21]. Statistical significance was set at a probability of $p<0.05$ for all analyses. Statistical analyses were performed using SPSS statistics version 21.0.

\section{Results \\ Participants}

Between 2010 and 2013, a total of 237 patients with breast or colon cancer were included in the original PACT study (Fig. 1). In total, 119 patients were randomized to the exercise intervention and 118 patients to the control group. $\mathrm{Pa}-$ tients randomized to the intervention group attended $83 \%$ (interquartile range 69-91\%) of the supervised sessions.

Four years post-baseline, 197 PACT participants were eligible and approached to participate in the 4 year post-baseline measurements, and finally $128(65.0 \%)$ participants signed informed consent. Sixteen PACT participants refused to participate in the 4-year post-baseline measurements, and 54 PACT participants did not respond for unknown reasons, also after one reminder had been sent. Patient characteristics were not significantly different between participating patients and non-participating eligible patients $(p>0.05)$.

At baseline, characteristics of all original PACT participants in the intervention and the usual care group were comparable (Table 1), except that participants in the intervention group showed higher education $(46.2 \%$ vs. $38.1 \%$, respectively), had more frequent triple negative breast cancer $(20.2 \%$ vs. $10.2 \%)$, and were more often post-menopausal ( $40.3 \%$ vs. $30.5 \%)$.

\section{Outcomes \\ Fatigue}

The effects of the 18-week aerobic and resistance exercise intervention on fatigue have been published previously $[6,7]$. In short, the exercise intervention showed positive effects on physical fatigue immediately after the program ending (18 weeks). At 36 weeks, this effect was no longer statistically significant (Fig. 2).

At 4 years post-baseline, only the dimension physical fatigue tended to be lower in the intervention group compared to the usual care group $(-1.13,95 \% \mathrm{CI}-2.45,0.20$, $\mathrm{ES}=0.22$ ). Compared to baseline, 4-year physical fatigue did not significantly differ in the intervention group $(-1.00$, $95 \% \mathrm{CI}-2.17,0.18)$ and the usual care group $(-0.55,95 \%$ 
Table 1 Baseline characteristics of participants of the original PACT study $(n=237)$ and responders post-baseline $(n=128)$

\begin{tabular}{|c|c|c|c|c|}
\hline & \multicolumn{2}{|l|}{ All participants } & \multicolumn{2}{|c|}{ Responders $\sim 4$ years post-baseline } \\
\hline & Intervention $n=119$ & Usual care $n=118$ & Intervention $n=70$ & Usual care $n=58$ \\
\hline \multicolumn{5}{|l|}{ Socio-demographical factors } \\
\hline Age (years) & $50.9 \pm 9.0$ & $50.6 \pm 8.6$ & $51.1 \pm 8.3$ & $51.6 \pm 7.9$ \\
\hline Sex, female & $109(91.6)$ & $107(90.7)$ & $64(91.4)$ & $53(91.4)$ \\
\hline \multicolumn{5}{|l|}{ Marital status } \\
\hline Couple & $91(76.5)$ & $87(73.7)$ & $59(84.3)$ & $48(82.8)$ \\
\hline Single & $24(20.2)$ & $25(21.2)$ & $11(15.7)$ & $10(17.2)$ \\
\hline \multicolumn{5}{|l|}{ Education } \\
\hline Low & $5(4.2)$ & $21(17.8)$ & $2(2.9)$ & $8(13.8)$ \\
\hline Medium & $55(46.2)$ & $46(39.0)$ & $36(51.4)$ & $22(37.9)$ \\
\hline High & $55(46.2)$ & $45(38.1)$ & $32(45.7)$ & $28(48.3)$ \\
\hline BMI $\left(\mathrm{kg} / \mathrm{m}^{2}\right)$ & $25.9 \pm 4.4$ & $26.5 \pm 5.0$ & $25.4 \pm 4.0$ & $25.6 \pm 4.2$ \\
\hline Postmenopausal & $48(40.3)$ & $36(30.5)$ & $27(38.6)$ & $17(29.3)$ \\
\hline \multicolumn{5}{|l|}{ Cancer-related factors } \\
\hline \multicolumn{5}{|l|}{ Tumor site } \\
\hline Breast cancer & $102(85.7)$ & $102(86.4)$ & $59(84.3)$ & $51(87.9)$ \\
\hline Colon cancer & $17(14.3)$ & 16 (13.6) & $11(15.7)$ & $7(12.1)$ \\
\hline \multicolumn{5}{|l|}{ Radiotherapy } \\
\hline Yes & $74(62.2)$ & $71(60.2)$ & $46(65.7)$ & 34 (58.6) \\
\hline No & $45(37.8)$ & $47(39.8)$ & $24(34.3)$ & $24(41.4)$ \\
\hline \multicolumn{5}{|l|}{ Tumor receptor status } \\
\hline Triple negative & $24(20.2)$ & $12(10.2)$ & $13(18.6)$ & $6(10.3)$ \\
\hline Her2+, ER+ or PR+ & $11(9.2)$ & $18(15.3)$ & $6(7.1)$ & $10(17.2)$ \\
\hline Her2+, ER- and PR- & $10(8.4)$ & $2(1.7)$ & $9(12.9)$ & - \\
\hline Her2-, ER+ or PR+ & $57(47.9)$ & $70(59.3)$ & $32(45.7)$ & $35(60.3)$ \\
\hline \multirow[t]{2}{*}{ Tissue expander } & $9(7.6)$ & $10(8.5)$ & $5(7.1)$ & $5(8.6)$ \\
\hline & Median & Median & Median & Median \\
\hline $\begin{array}{l}\text { Moderate-to-high intensity total PA } \\
\text { performed before diagnosis (min/week) }\end{array}$ & 485 [240-975] & 600 [300-1440] & 450 [233-1005] & 720 [375-1540] \\
\hline $\begin{array}{l}\text { Moderate -to-high intensity leisure and sport PA } \\
\text { levels performed before diagnosis (min/week) }\end{array}$ & $180[50-375]$ & 173 [60-330] & $180[60-315]$ & 180 [60-345] \\
\hline
\end{tabular}

Continuous variables are presented as mean \pm SD or as median and interquartile range, whereas dichotomous or categorical variables are presented as $n$ (\%) $B M I$ body mass index, ER estrogen receptor, $P R$ progesterone receptor, $P A$ physical activity, SD standard deviation

CI $-1.79,0.70)$. No significant differences were found for the other dimensions of fatigue (Table 2).

\section{Physical activity}

The effects of the 18-week exercise intervention on physical activity levels have not been published previously. In short, moderate-to-vigorous total physical activity levels as well as leisure-time and sport physical activity levels significantly decreased from pre-diagnostic to 18 weeks (post-intervention) and 36 weeks post-baseline in both study arms (i.e., during adjuvant treatment) (Fig. 2). Four years post-baseline, participants resumed their pre-diagnostic physical activity levels. Compared to baseline, combined moderate-to-vigorous leisure-time and sport physical activity levels in the intervention group were significantly higher 4 years post-baseline $(85.18 \mathrm{~min} /$ week, $95 \%$ CI 30.65, 139.72) (Table 2). Moreover, compared to the usual care group, participants in the intervention group reported significantly higher moderate-to-vigorous total physical activity levels (141.46 $\mathrm{min} /$ week, 95\% CI 1.31, 281.61, $\mathrm{ES}=0.22$ ) 4 years post-baseline. Moderate-to-vigorous leisure-time and sport physical activity did not differ significantly (20.41 min/week, 95\% CI - 45.54, 86.36, ES = 0.08).

Results for fatigue and physical activity in breast cancer participants only were attenuated, but in general comparable to results for the total group (Table 3). 


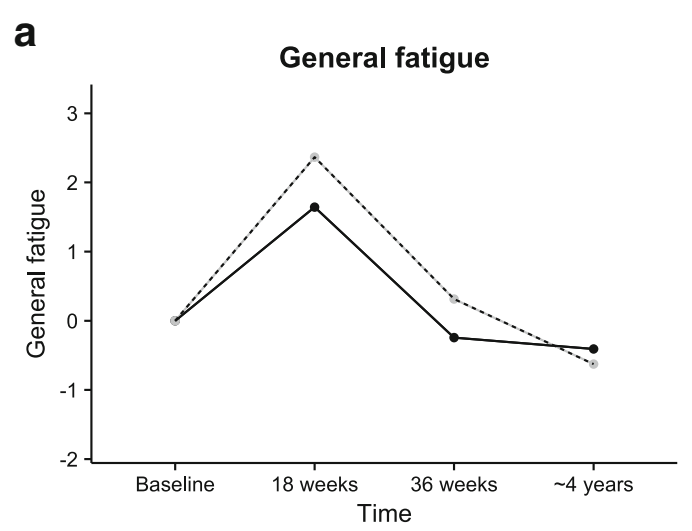

C

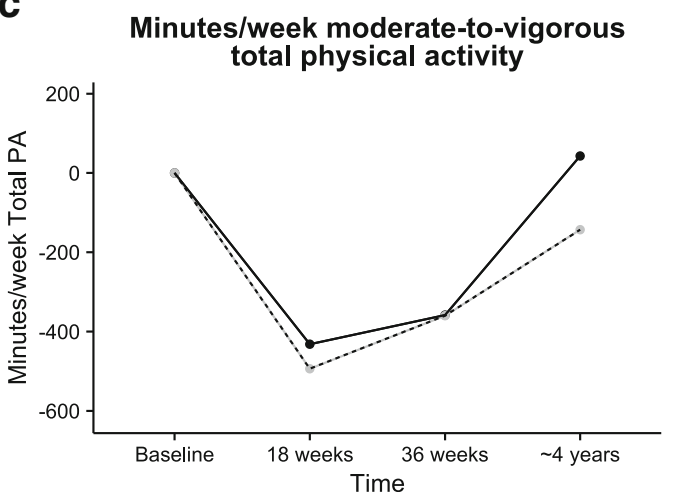

b

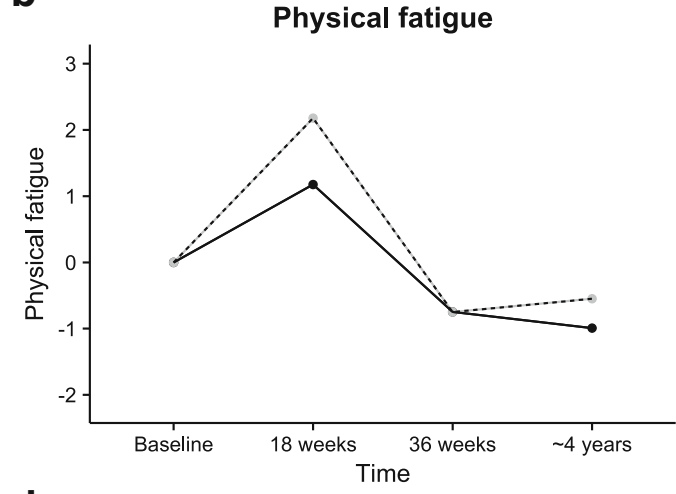

d

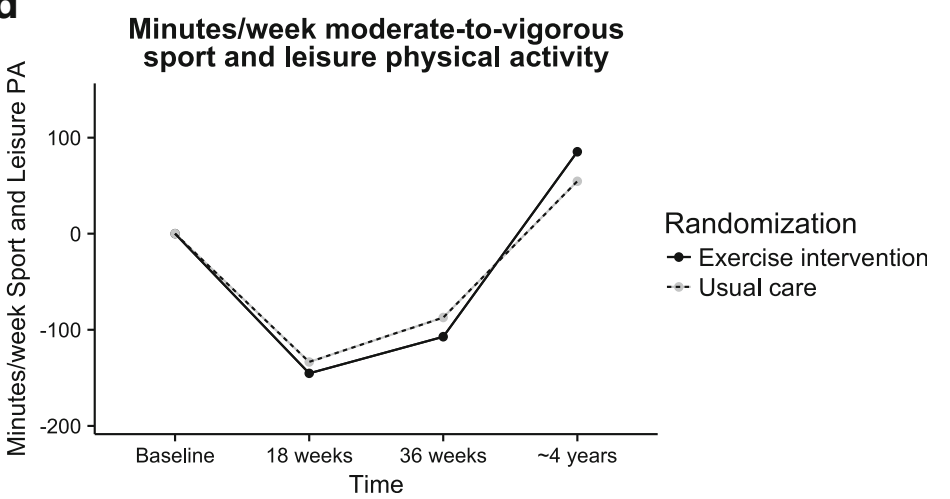

Fig. 2 Effect of the exercise intervention on fatigue and physical activity levels over time. Intention-to-treat mixed linear regression models were used to model absolute changes in a general fatigue, $\mathbf{b}$ physical fatigue, $\mathbf{c}$ total physical activity, and $\mathbf{d}$ sport and leisure-time physical activity from baseline to 18 weeks, 36 weeks, and 4 years for all breast and colon cancer patients

\section{Discussion}

Cancer-related fatigue is a common side effect of chemotherapy. Exercise during chemotherapy might be a promising strategy for minimizing treatment-related side effects, both short term and long term $[4,9,11,22]$. The present study assessed long-term effects of the PACT exercise intervention on fatigue and physical activity levels in patients with breast or colon cancer approximately 4 years after enrollment in the original PACT study. Breast and colon cancer patients who participated in the 18-week exercise intervention showed non-significant lower levels of physical fatigue and significant higher levels of physical activity approximately 4 years post-baseline.

In the original PACT study, physical fatigue increased significantly less in the intervention group compared to the control group during the 18-week exercise intervention [6]. Slightly lower levels of physical fatigue in participants in the intervention group were still observed after 4 years, although this was not statistically significant. This is probably due to the slightly reduced power, since only a sample of all eligible PACT participants participated in the measurements 4 years post-baseline. Nonetheless, the ES of the original randomized controlled PACT study was of comparable magnitude ( $\mathrm{ES}=0.27 \quad 18$ weeks (post-intervention) vs.
ES $=0.224$ years post-baseline). So far, no other studies have investigated the long-term effects, i.e., several years post-intervention, of exercise during cancer treatment on fatigue. Since fatigue is known to be a long-lasting side effect of cancer treatment, it is important to develop interventions that reduce fatigue both in the short and long terms. More research is needed to confirm our indicative finding that exercising during chemotherapy might be a promising strategy for minimizing fatigue in the long term.

Although physical activity levels during the PACT intervention period did not differ between groups, at 4-year follow-up, participants who were randomized to the intervention group reported higher moderate-to-vigorous physical activity levels than participants randomized to the usual care group. This is a favorable result, since the PACT study was designed to promote maintenance of a physically active lifestyle by incorporating cognitive behavioral principles of Bandura's social cognitive theory [8]. Also, in addition to the PACT exercise intervention, participants were encouraged to be physically active for at least $30 \mathrm{~min}$ on at least 3 other days. This recommendation might have made them more aware of the importance of integrating physical activity in daily life. According to Cohen, the ES of 0.22 can be indicated as a small 
Table 2 Long-term effects of exercise on fatigue and physical activity among colon and breast cancer patients

\begin{tabular}{|c|c|c|c|c|c|c|}
\hline & & \multirow{2}{*}{\multicolumn{2}{|c|}{ Baseline }} & \multicolumn{2}{|c|}{ Baseline to 4 years post-intervention } & \multirow[b]{3}{*}{ Effect size } \\
\hline & & & & \multirow{2}{*}{$\begin{array}{l}\text { Within-group differences } \\
\text { Mean }[95 \% \mathrm{Cl}]\end{array}$} & \multirow{2}{*}{$\begin{array}{l}\text { Between-group differences } \\
\text { Mean }[95 \% \mathrm{Cl}]\end{array}$} & \\
\hline & & Mean & SD & & & \\
\hline \multicolumn{7}{|l|}{ Multidimensional Fatigue Inventory (MFI) } \\
\hline \multirow[t]{2}{*}{ General fatigue } & 1 & 10.24 & 4.92 & $-0.41[-1.52,0.71]$ & $-0.38[-1.63,0.86]$ & 0.08 \\
\hline & UC & 10.67 & 4.80 & $-0.63[-1.81,0.56]$ & Reference & \\
\hline \multirow[t]{2}{*}{ Physical fatigue } & । & 9.92 & 5.12 & $-1.00[-2.17,0.18]$ & $-1.13[-2.45,0.20]$ & 0.22 \\
\hline & UC & 10.54 & 5.01 & $-0.55[-1.79,0.70]$ & Reference & \\
\hline \multirow[t]{2}{*}{ Mental fatigue } & । & 9.77 & 5.33 & $-0.23[-1.40,0.94]$ & $-0.30[-1.64,1.05]$ & 0.06 \\
\hline & UC & 9.96 & 5.20 & $-0.24[-1.48,1.00]$ & Reference & \\
\hline \multirow[t]{2}{*}{ Reduced activity } & I & 8.18 & 4.11 & $-0.38[-1.28,0.53]$ & $-0.17[-1.23,0.90]$ & 0.04 \\
\hline & UC & 8.91 & 4.02 & $-0.98[-1.94,-0.02]^{*}$ & Reference & \\
\hline \multirow[t]{2}{*}{ Reduced motivation } & I & 8.36 & 5.51 & $0.72[-0.41,1.85]$ & $-0.18[-1.15,0.79]$ & 0.03 \\
\hline & UC & 9.17 & 5.83 & $0.40[-0.81,1.61]$ & Reference & \\
\hline \multicolumn{7}{|c|}{ Short Questionnaire of Assess Health-enhancing physical activity (SQUASH) } \\
\hline Total physical activity & I UC & $\begin{array}{l}583.91 \\
627.31\end{array}$ & $\begin{array}{l}658.73 \\
637.11\end{array}$ & $\begin{array}{l}43.22[-102.13,188.57] \\
-143.77[-298.43,10.89]\end{array}$ & $\begin{array}{l}141.46[1.31,281.61]^{*} \\
\text { Reference }\end{array}$ & 0.22 \\
\hline Sport and leisure physical activity & UC & $\begin{array}{l}220.08 \\
227.34\end{array}$ & $\begin{array}{l}269.27 \\
259.91\end{array}$ & $\begin{array}{l}85.18[30.65,139.72]^{*} \\
54.67[-3.75,113.09]\end{array}$ & $\begin{array}{l}20.41[-45.54,86.36] \\
\text { Reference }\end{array}$ & 0.08 \\
\hline
\end{tabular}

I exercise intervention group, UC usual care group, $S D$ standard deviation, $C l$ confidence interval

* Statistically significant $(p<0.05)$

Between-group effects were assessed using mixed models including the measurements obtained at 18 and 36 weeks and 4 years, adjusted for the value of the outcome variable at baseline as well as for stratification factors: age, radiotherapy, hospital, and tumor site. Within-group effects were assessed using mixed models including the measurements obtained at baseline, 18 and 36 weeks, and 4 years, adjusted for stratification factors: age, radiotherapy, hospital, and tumor site

Baseline results and within-group differences were based on participants having baseline measurements. Between-group differences were based on participants having measurements at 18 weeks, 36 weeks, or 4 years

difference; however, given the beneficial effects of physical activity on treatment-related side effects and prognosis, every gain in moderate-to-high intensity physical activity might be clinically relevant.

The observed effects of an exercise intervention on subsequent higher physical activity levels are comparable to results of Mutrie et al. [14], who also performed a long-term follow-up. The study included 203 patients with breast cancer in a 12-week supervised group exercise program starting during treatment for early stage breast cancer [14]. Higher leisure-time physical activity levels were observed in the intervention group compared to the control group 5 years after the intervention. The present study found higher total physical activity levels in the intervention group compared to the usual care group. In addition, they found that those who maintained a physically active lifestyle 5 years after cancer treatment still benefit in terms of increased quality of life and lower levels of depression [14]. The PACThe trial, which offered a 2-week physical and educational intervention to patients with breast cancer post-chemotherapy, found a significant improvement in breast cancer survivors' quality of life at 5-year follow-up [23]. Results of these studies suggest that, for both breast and colon cancer survivors, engaging in exercise during chemotherapy and maintaining a physically active lifestyle into survivorship might be important for enhanced well-being in the long term. In order to optimize the long-term benefits of physical activity, more research is needed to unravel the best ways to support cancer survivors to maintain a regular exercise routine.

Our results should be viewed within the context of several strengths and limitations. Strong features of this study are the randomized design of the original PACT study, the long-term follow-up measurements 4 years post-baseline, and the intention-to-treat analyses. The present study also suffered some limitations. Only 65\% of PACT participants responded, which was higher compared to the response rate in the study of Mutrie et al. [14] (42\%). Nonetheless, baseline characteristics of participating patients did not significantly differ from characteristics of non-participating eligible patients. Participants in this study reported, on average, high pre-diagnostic physical activity levels and, therefore, might not be the ones who benefited from this exercise program the most. In the current study, due to the small number of patients with colon cancer, we analyzed our data for breast and colon cancer patients together, although benefits resulting from exercise may vary depending on treatment modality and tumor type. In previous 
Table 3 Long-term effect of exercise on fatigue and physical activity among breast cancer patients only

\begin{tabular}{|c|c|c|c|c|c|c|}
\hline & & \multirow{2}{*}{\multicolumn{2}{|c|}{ Baseline }} & \multicolumn{2}{|c|}{ Baseline to 4 years post-intervention } & \multirow[b]{3}{*}{ Effect size } \\
\hline & & & & \multirow{2}{*}{$\begin{array}{l}\text { Within-group differences } \\
\text { Mean }[95 \% \mathrm{Cl}]\end{array}$} & \multirow{2}{*}{$\begin{array}{l}\text { Between-group differences } \\
\text { Mean }[95 \% \mathrm{Cl}]\end{array}$} & \\
\hline & & Mean & SD & & & \\
\hline \multicolumn{7}{|l|}{ Multidimensional Fatigue Inventory (MFI) } \\
\hline \multirow[t]{2}{*}{ General fatigue } & । & 9.28 & 6.08 & $0.13[-1.11,1.38]$ & $-0.26[-1.65,1.12]$ & 0.04 \\
\hline & UC & 10.01 & 6.11 & $-0.48[-1.78,0.82]$ & Reference & \\
\hline \multirow[t]{2}{*}{ Physical fatigue } & । & 9.05 & 6.32 & $-0.53[-1.83,0.76]$ & $-1.05[-2.53,0.43]$ & 0.17 \\
\hline & UC & 10.01 & 6.35 & $-0.33[-1.68,1.02]$ & Reference & \\
\hline \multirow[t]{2}{*}{ Mental fatigue } & । & 9.32 & 6.64 & $0.05[-1.24,1.33]$ & $-0.09[-1.59,1.41]$ & 0.01 \\
\hline & UC & 9.77 & 6.68 & $-0.28[-1.62,1.06]$ & Reference & \\
\hline \multirow[t]{2}{*}{ Reduced activity } & । & 7.04 & 5.07 & $-0.21[-1.21,0.79]$ & $0.17[-1.02,1.36]$ & 0.03 \\
\hline & UC & 7.62 & 5.09 & $-0.95[-1.98,0.09]$ & Reference & \\
\hline \multirow[t]{2}{*}{ Reduced motivation } & । & 7.92 & 6.42 & $0.51[-0.73,1.74]$ & $-0.20[-1.27,0.87]$ & 0.03 \\
\hline & UC & 8.42 & 6.71 & $0.39[-0.91,1.70]$ & Reference & \\
\hline \multicolumn{7}{|c|}{ Short Questionnaire to Assess Health-enhancing physical activity (SQUASH) } \\
\hline Total physical activity & I UC & $\begin{array}{l}640.55 \\
750.38\end{array}$ & $\begin{array}{l}794.85 \\
792.05\end{array}$ & $\begin{array}{l}36.76[-125.46,198.98] \\
-167.21[-336.75,2.32]\end{array}$ & $\begin{array}{l}117.70[-40.61,276.02] \\
\text { Reference }\end{array}$ & 0.15 \\
\hline Sport and leisure physical activity & I & $\begin{array}{l}211.59 \\
217.57\end{array}$ & $\begin{array}{l}332.60 \\
332.04\end{array}$ & $\begin{array}{l}93.91[32.33,155.49]^{*} \\
56.71[-8.03,121.45]\end{array}$ & $\begin{array}{l}33.66[-40.26,107.57] \\
\text { Reference }\end{array}$ & 0.10 \\
\hline
\end{tabular}

I exercise intervention group, UC usual care group, $S D$ standard deviation, $\mathrm{Cl}$ confidence interval

* Statistically significant $(p<0.05)$

Between-group effects were assessed using mixed models including the measurements obtained at 18 and 36 weeks and 4 years, adjusted for tumor receptor status and the value of the outcome variable at baseline as well as for stratification factors: age, radiotherapy, hospital, and tissue expander. Within-group effects were assessed using mixed models including the measurements obtained at baseline, 18 and 36 weeks, and 4 years, adjusted for tumor receptor status as well as for stratification factors: age, radiotherapy, hospital, and tissue expander

Baseline results and within-group differences were based on participants having baseline measurements. Between-group differences were based on participants having measurements at 18 weeks, 36 weeks, or 4 years

analyses, a significant effect of the intervention on physical fatigue was observed at 18 weeks for both sites, but the effect was larger for colon cancer patients [6, 7]. Another limitation of our study includes the reliance on self-reported measures of physical activity, since these measures are prone to over-reporting. Objective measurement of physical activity would overcome this limitation and could provide a more valid estimate of physical activity in future studies [24, 25]. Nonetheless, subjectively measured physical activity using the SQUASH has been shown to be reliable [19], and we do not expect differential over-reporting in this 4-year follow-up. Finally, the lack of detailed information on patients who refused participation might have hampered the generalizability of the results.

\section{Conclusion}

This study shows that an 18-week exercise intervention offered in daily clinical practice and started during early adjuvant treatment including chemotherapy has beneficial long-term effects. These beneficial effects include significantly higher levels of moderate-to-vigorous total physical activity levels and non-significant lower physical fatigue levels 4 years post-baseline. These results emphasize that facilitation of physical activity during cancer treatment may enhance health outcomes in both the short and long terms.

\section{Abbreviations}

Cl: Confidence interval; ES: Effect size; MET: Metabolic equivalent; MFI: Multifactorial Fatigue Inventory; PACT: Physical Activity during Cancer Treatment; RCT: Randomized controlled trial; SQUASH: Short Questionnaire to Assess Health-enhancing physical activity; SD: Standard deviation

\section{Acknowledgements}

We would like to thank the participants and the professional staff at St. Antonius Hospital, Nieuwegein and Utrecht; Diakonessenhuis Hospital, Utrecht; Meander Medical Centre, Amersfoort; Rivierenland Hospital, Tiel; Orbis Medical Center, Sittard; Zuwe Hofpoort Hospital, Woerden; and University Medical Center Utrecht, The Netherlands. Their participation made this study possible.

\section{Funding}

This work was supported by The Netherlands Organisation for Health Research and Development (ZonMw, project numbers 171002202 and 016156050), the Dutch Cancer Society (KWF Kankerbestrijding, project number UU 2009-4473), the Dutch Pink Ribbon Foundation (2011.WO02.C100), and VIOZ (Stichting Vrienden Integrale Oncologische Zorg) 2015. The funders had no role in study design, data collection and analysis, decision to publish, or preparation of the manuscript.

\section{Availability of data and materials}

The datasets used and/or analyzed during the current study are available from the corresponding author on reasonable request.

\section{Authors' contributions}

MJV, PHMP, EW, and AMM initiated the collaborative project. MJV, ML, FLGE, HJB, MV, DBH, PHMP, EW, and AMM planned the project. LW, AEH, MJV, CNSB, and AMM collected the data. ML, FLGE, HJB, MV, DBH, and EW provided the clinical expertise. LW, AEH, MJV, CNSB, PHMP, and AMM were responsible for data handling and data analysis. ML, FLGE, HJB, MV, and DBH recruited participants. LW, $\mathrm{AEH}$, and $\mathrm{AMM}$ wrote the first draft, and all authors contributed and approved the final version of the manuscript for publication. 


\section{Ethics approval and consent to participate}

The study was approved by the Medical Ethics Committee of the University Medical Center Utrecht and the local ethical boards of the participating hospitals (i.e., St. Antonius Hospital, Nieuwegein; Diakonessenhuis Hospital, Utrecht; Meander Medical Centre, Amersfoort; Rivierenland Hospital, Tiel; Orbis Medical Center, Sittard; Zuwe Hofpoort Hospital, Woerden). All participants signed informed consent.

\section{Competing interests}

The authors declare that they have no competing interests.

\section{Publisher's Note}

Springer Nature remains neutral with regard to jurisdictional claims in published maps and institutional affiliations.

\section{Author details}

'Department of Clinical Epidemiology, Julius Center for Health Sciences and Primary Care, University Medical Center Utrecht, Utrecht University, PO Box 85500, STR 6.131, 3508 GA Utrecht, The Netherlands. ${ }^{2}$ Netherlands Comprehensive Cancer Organisation (IKNL), PO Box 19079, 3501 DB Utrecht, The Netherlands. ${ }^{3}$ Department of Medical Oncology, St. Antonius Ziekenhuis, Koekoekslaan 1, 3435 CM Nieuwegein, The Netherlands. ${ }^{4}$ Department of Internal Medicine - Medical Oncology, Obis Medisch Centrum, Dr van der Hoffplein 1, 6166 BG Sittard-Geleen, The Netherlands. ${ }^{5}$ Department of Internal Medicine, Meander Medical Center, Maatweg 3, 3818 TZ Amersfoort, The Netherlands. ${ }^{6}$ Department of Internal Medicine, Hofpoort Ziekenhuis, Polanerbaan 2, 3447 GN Woerden, The Netherlands. 'Department of Internal Medicine, Diakonessenhuis, Bosboomstraat 1, 3582 KE Utrecht, The Netherlands. ${ }^{8}$ Department of Medical Oncology, University Medical Center Utrecht, Utrecht University, Heidelberglaan 100, 3584 CX Utrecht, The Netherlands.

Received: 29 December 2017 Accepted: 14 May 2018 Published online: 08 June 2018

\section{References}

1. Cleeland CS, Zhao F, Chang VT, Sloan JA, O'Mara AM, Gilman PB, et al. The symptom burden of cancer: evidence for a core set of cancer-related and treatment-related symptoms from the Eastern Cooperative Oncology Group Symptom Outcomes and Practice Patterns study. Cancer. 2013;1 19(24):4333-40.

2. Stan D, Loprinzi C, Ruddy K. Breast cancer survivorship issues. Hematol Oncol Clin North Am. 2013;27(4):805-27.

3. Bower J, Ganz P, Desmond K, Rowland J, Meyerowitz B, Belin T, et al. Fatigue in breast cancer survivors: occurrence, correlates, and impact on quality of life. J Clin Oncol. 2000;18(4):743-53.

4. Furmaniak A, Menig M, Markes M. Exercise for women receiving adjuvant therapy for breast cancer. Cochrane Database Syst Rev. 2016;9:CD005001.

5. Van Vulpen JK, Peeters PHM, Velthuis MJ, Van Der Wall E, May AM. Effects of physical exercise during adjuvant breast cancer treatment on physical and psychosocial dimensions of cancer-related fatique: a meta-analysis. Maturitas. 2016;85:104-11.

6. Travier N, Velthuis MJ, Steins Bisschop CN, van den Buijs B, Monninkhof EM, Backx F, et al. Effects of an 18-week exercise programme started early during breast cancer treatment: a randomised controlled trial. BMC Med. 2015;13:121.

7. Van Vulpen JK, Velthuis MJ, Bisschop CNS, Travier N, Van Den Buijs BJW, BackX FJG, et al. Effects of an exercise program in colon cancer patients undergoing chemotherapy. Med Sci Sports Exerc. 2016;48(5):767-75.

8. Bandura A. Social foundations of thought and action: a social cognitive theory. Englewood Cliffs: Prentice-Hall; 1986.

9. Juvet LK, Thune I, Elvsaas IKØ, Fors EA, Lundgren S, Bertheussen G, et al. The effect of exercise on fatigue and physical functioning in breast cancer patients during and after treatment and at 6 months follow-up: a metaanalysis. Breast. 2017;33:166-77.

10. Miller KD, Siegel RL, Lin CC, Mariotto AB, Kramer JL, Rowland JH, et al. Cancer treatment and survivorship statistics, 2016. CA Cancer J Clin. 2016; 66(4):271-89.

11. Van Waart H, Stuiver MM, Van Harten WH, Geleijn E, Kieffer JM, Buffart LM, et al. Effect of low-intensity physical activity and moderate- to high-intensity physical exercise during adjuvant chemotherapy on physical fitness, fatigue, and chemotherapy completion rates: results of the PACES randomized clinical trial. J Clin Oncol. 2015;33(17):1918-27.
12. Courneya KS, Segal RJ, Gelmon K, Reid RD, Mackey JR, Friedenreich CM, et al. Six-month follow-up of patient-rated outcomes in a randomized controlled trial of exercise training during breast cancer chemotherapy. Cancer Epidemiol Biomark Prev. 2007;16(12):2572-8.

13. Mutrie N, Campbell AM, Whyte F, McConnachie A, Emslie C, Lee L, et al. Benefits of supervised group exercise programme for women being treated for early stage breast cancer: pragmatic randomised controlled trial. BMJ. 2007;334(7592):517.

14. Mutrie N, Campbell A, Barry S, Hefferon K, McConnachie A, Ritchie D, et al. Five-year follow-up of participants in a randomised controlled trial showing benefits from exercise for breast cancer survivors during adjuvant treatment. Are there lasting effects? J Cancer Surviv. 2012;6(4):420-30.

15. Trinh L, Mutrie N, Campbell AM, Crawford JJ, Courneya KS. Effects of supervised exercise on motivational outcomes in breast cancer survivors at 5-year follow-up. Eur J Oncol Nurs. 2014;18(6):557-63. Available from: https://doi.org/10.1016/j.ejon.2014.07.004

16. Velthuis MJ, May AM, Koppejan-Rensenbrink RA, Gijsen BCM, van Breda E, de Wit GA, et al. Physical Activity during Cancer Treatment (PACT) Study: design of a randomised clinical trial. BMC Cancer. 2010;10:272.

17. Kemper H, Ooijendijk W, Stiggelbout M. Consensus about the Dutch physical activity guideline. Tijdschr Soc Geneeskd. 2000;78:180-3.

18. Smets EMA, Garssen B, Bonke B, De Haes JCJM. The Multidimensional Fatigue Inventory (MFI) psychometric qualities of an instrument to assess fatigue. J Psychosom Res. 1995;39(3):315-25.

19. Wendel-Vos GCW, Schuit AJ, Saris WHM, Kromhout D. Reproducibility and relative validity of the Short Questionnaire to Assess Health-enhancing physical activity. J Clin Epidemiol. 2003;56(12):1163-9.

20. Borm GF, Fransen J, Lemmens WAJG. A simple sample size formula for analysis of covariance in randomized clinical trials. J Clin Epidemiol. 2007; 60(12):1234-8.

21. Cohen J. Statistical power analysis for the behavioral sciences. 2nd ed. Hillsdale: Lawrence Erlbaum; 1988.

22. Duregon F, Vendramin B, Bullo V, Gobbo S, Cugusi L, Di Blasio A, et al. Effects of exercise on cancer patients suffering chemotherapy-induced peripheral neuropathy undergoing treatment: a systematic review. Crit Rev Oncol Hematol. 2018;121:90-100.

23. Kwiatkowski F, Mouret-Reynier M-A, Duclos M, Bridon F, Hanh T, Van Praagh-Doreau I, et al. Long-term improvement of breast cancer survivors' quality of life by a 2-week group physical and educational intervention: 5year update of the "PACThe" trial. Br J Cancer. 2017;116(11):1389-93.

24. Harris TJ, Owen CG, Victor CR, Adams R, Ekelund ULF, Cook DG. A comparison of questionnaire, accelerometer, and pedometer: measures in older people. Med Sci Sports Exerc. 2009;41(7):1392-402.

25. Neill BO, Mcdonough SM, Wilson JJ, Bradbury I, Hayes K, Kirk A, et al. Comparing accelerometer, pedometer and a questionnaire for measuring physical activity in bronchiectasis: a validity and feasibility study? Respir Res. 2017;18(1):16

\section{Ready to submit your research? Choose BMC and benefit from:}

- fast, convenient online submission

- thorough peer review by experienced researchers in your field

- rapid publication on acceptance

- support for research data, including large and complex data types

- gold Open Access which fosters wider collaboration and increased citations

- maximum visibility for your research: over $100 \mathrm{M}$ website views per year

At BMC, research is always in progress.

Learn more biomedcentral.com/submissions 